\title{
Perfil eletroforético do proteinograma sérico de eqüinos com obstrução experimental do cólon menor
}

\author{
[Eletrophoretic profile of serum proteinogram of equines with small colon experimental obstruction]

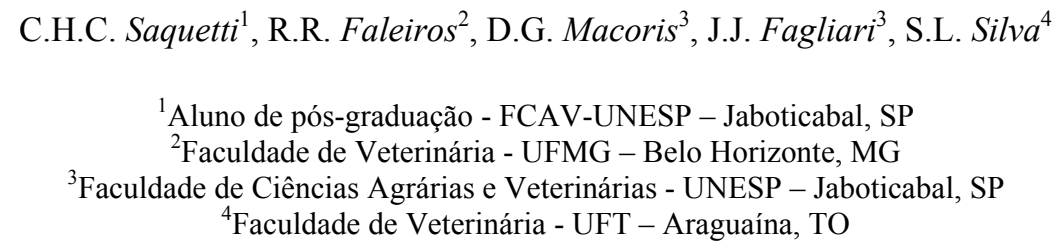

\section{RESUMO}

Avaliaram-se as alterações do proteinograma sérico de eqüinos submetidos à isquemia e reperfusão do cólon menor por distensão intraluminal. Foram utilizados 10 animais submetidos à laparotomia pelo flanco, em posição quadrupedal, para a indução de obstrução no cólon menor durante um período de quatro horas. Cinco animais foram instrumentados, mas sem distensão (grupo controle - G1). Em cinco outros animais, foi realizada isquemia mural por distensão do cólon menor via manguito inflado com 40mmHg (grupo distendido - G2). Foram colhidas amostras de sangue antes da intervenção cirúrgica (M1), com 4 horas da colocação do manguito (M2) e com 3 horas (M3) e 12 horas (M4) de reperfusão. Após centrifugação e fracionamento das amostras, as proteínas de fase aguda foram separadas por eletroforese em gel de poliacrilamida contendo SDS-PAGE, e suas concentrações determinadas por densitometria computadorizada. Foram encontradas 19 proteínas no fracionamento eletroforético, com peso molecular variando de 185.000 a 14.000 Daltons (Da). Os pesos moleculares encontrados, correspondentes às proteínas mais conhecidas, foram ceruloplasmina, $130.000 \mathrm{Da}$; proteína C-reativa, 122.000 Da; transferrina, $85.000 \mathrm{Da}$; $\alpha_{1}$ antitripsina, $61.000 \mathrm{Da}$; haptoglobina, 47.000 Da; e glicoproteína ácida, $40.000 \mathrm{Da}$. Os resultados mostram que proteínas de fase aguda se alteram após o trauma cirúrgico.

Palavras-chave: eqüino, proteinograma, cólon menor, distensão intraluminal

\section{SUMMARY}

The changes in the serum proteinogram of equines submitted to ischemia and reperfusion of small colon by intraluminal distension were evaluated. Ten horses were submitted to standing laparotomy to induce a small colon obstruction for four hours. Five animals were instrumented without distention (control group - G1). In another five animals, mural ischemia was promoted placing a latex balloon distended with $40 \mathrm{mmHg}$ into the small colon (distended group - G2). Blood samples were collected before the surgical procedures (M1) and $4 \mathrm{~h}$ after the balloon placement (M2) and $3 \mathrm{~h}$ (M3) and $12 \mathrm{~h}$ (M4) after reperfusion. After centrifugation and fractioning of the samples, the acute phase proteins were separated by SDS$P A G E$ and their concentrations were determined by computer densitometry. Nineteen proteins were separated by eletrophoresis and the molecular weights ranged from 185,000 to 14,000 Dalton (Da). The found molecular weights, related to the most known proteins, were: ceruloplasmin, 130,000 Da; Creactive protein, 122,000 Da; transferrin, 85,000 Da; $\alpha_{1}$-antitripsin, 61,000 Da; haptoglobin, 47,000 Da; and acid glycoprotein, 40,000 Da. The results showed that acute phase proteins changed after surgical injury.

Keywords: equine, proteinogram, small colon, intraluminal distension

Recebido em 24 de maio de 2007

Aceito em 4 de abril de 2008

E-mail: carlossaquetti@yahoo.com.br 


\section{INTRODUÇÃO}

Trabalho realizado por Silva et al. (1998) mostrou que $30,9 \%$ das afecções cirúrgicas do intestino grosso de eqüinos ocorrem no cólon menor, e a maioria delas é de obstruções intraluminais. Faleiros et al. (2002a) acreditam que, em eqüinos criados ao redor de grandes centros, a nutrição improvisada e a constante ingestão de poluentes, como sacolas plásticas, contribuem para elevar essa estatística.

A endotoxemia, a isquemia e a reperfusão, a infecção, os procedimentos cirúrgicos e os processos inflamatórios induzem à resposta inicial do organismo, que inclui alterações fisiológicas denominadas resposta de fase aguda da inflamação. Dentre essas alterações, está a modificação do metabolismo hepático, com aumento da produção de glicoproteínas denominadas proteínas de fase aguda (PFA) (Takiguchi et al., 1990) que começam a ser detectadas quatro horas após a indução do dano (Fagliari et al., 1997).

As proteínas de fase aguda podem ser classificadas como positivas ou negativas (Kaneko et al., 1997). No primeiro grupo, enquadram-se, dentre outras, a glicoproteína ácida e a haptoglobina (Takiguchi et al., 1990). No segundo grupo, destacam-se a albumina e a transferrina, cujos níveis séricos tendem a decrescer na presença de condições inflamatórias (Kaneko et al., 1997).

O fracionamento eletroforético representa um dos mais confiáveis métodos de identificação e quantificação de proteínas dos fluidos corporais (Kaneko et al., 1997). Gordon (1995) relatou que o uso de eletroforese em gel de poliacrilamida contendo dodecil sulfato de sódio (SDS-PAGE) possibilita a detecção de concentrações protéicas extremamente baixas e a identificação de 20 a 30 proteínas, utilizando-se micro-quantidades de amostra, enquanto outras técnicas utilizadas, como a fita de acetato de celulose ou o filme de agarose, possibilitam apenas a identificação de cinco a sete grupos de proteínas (Mattews, 1982; Edinger et al., 1992). Segundo Fagliari et al. (2006), a grande vantagem da técnica de SDSPAGE é a possibilidade de identificação de maior número proteínas específicas, em especial imunoglobulina $\mathrm{G}$ e as proteínas de fase aguda.
Pesquisas mostram que a proteína c-reativa em cães é análoga à proteína c-reativa em humanos, e tem-se demonstrado que, no pós-cirúrgico em cães, há aumento dessa proteína quatro horas após a intervenção, enquanto em humanos, isso ocorre seis horas após (Conner et al., 1988).

Para a espécie eqüina, consideram-se como as mais importantes proteínas de fase aguda a ceruloplasmina, a proteína c-reativa, a haptoglobina e a glicoproteína ácida (Nunokawa et al., 1993).

Poucas pesquisas têm sido realizadas associando os perfis das PFA aos quadros de abdômen agudo eqüino. Segundo Takiguchi et al. (1990), o proteinograma plasmático auxilia no diagnóstico de quadros clínicos suspeitos de septicemia ou endotoxemia e em complicações pós-operatórias em eqüinos.

O presente estudo teve por objetivo avaliar as alterações no proteinograma sérico de eqüinos submetidos à isquemia e reperfusão do cólon menor por obstrução intraluminal.

\section{MATERIAL E MÉTODOS}

O experimento foi realizado com 10 animais hígidos, machos e fêmeas, sem raça definida, com idade de $7 \pm 2,3$ anos, peso de $333 \pm 40 \mathrm{~kg}$ e escore corporal entre 2,5 a 3,5, conforme classificação de Speirs (1997). Nesses animais, foram realizadas avaliações clínica e hematológica, para confirmar a ausência de anemia, infecções ou outras alterações que os comprometessem.

Os animais foram divididos em dois grupos: cinco foram instrumentados, mas não tiveram o manguito inflado (grupo-controle - G1); em cinco outros, o manguito foi inflado com ar até atingir 40mmHg (grupo distendido - G2), pressão capaz de reduzir, em média, $73,6 \%$ da perfusão na microcirculação da parede intestinal conforme relatos de Faleiros et al. (2002b).

Os animais, após jejum alimentar de $12 \mathrm{~h}$, foram sedados com xilazina ${ }^{1} 10 \% \quad(0,5 \mathrm{mg} / \mathrm{kg}$ IV $)$ e butorfanol $^{2}(0,1 \mathrm{mg} / \mathrm{kg} \mathrm{IM})$ e tiveram o flanco

${ }^{1}$ Sedazine-Fort Dodge - Campinas, Brasil.

${ }^{2}$ Torbugesic-Fort Dodge - Campinas, Brasil. 
esquerdo anestesiado por meio da técnica de "L" invertido com bupivacaína ${ }^{3} \quad 0,5 \%$ associada à lidocaína ${ }^{4} 2 \%$ sem vasoconstritor, após ter sido feita a tricotomia e a antissepsia cirúrgica. Delimitou-se um segmento inicial do cólon menor, aproximadamente a $50 \mathrm{~cm}$ da transição com o cólon transverso, e realizou-se a indução da obstrução intraluminal. Seguindo o modelo descrito por Faleiros et al. (2002b), o segmento exposto foi submetido à enterotomia na borda antimesentérica para colocação de um manguito de, aproximadamente, $15 \mathrm{~cm}$ de diâmetro, acoplado a um equipo de soro com uma pêra insufladora em sua extremidade. A pressão no interior do manguito foi registrada e monitorada por meio de um fisiógrafo ${ }^{5}$ devidamente calibrado. Para evitar o deslocamento do manguito, em direção oral ou aboral, foram colocadas, em ambas as extremidades do segmento, ligaduras feitas com dreno de Penrose $\mathrm{n}^{\mathrm{0}} 3$ ao redor do cólon menor, aplicada de modo a não ocluir a irrigação mesentérica nem a mural. Realizou-se, então, a enterorrafia com sutura simples contínua perfurante total no primeiro plano, e no segundo plano, em padrão cushing, ambas feitas com fio poliglactina $910^{6} 00$, mantendo-se o equipo por entre as bordas da ferida. Após o procedimento, os segmentos das alças expostos foram lavados com solução de Ringer com lactato e recolocados na cavidade. A incisão no flanco foi fechada com técnica de rotina, deixando-se o equipo sair por entre as bordas da ferida.

Após três horas da colocação do manguito, os animais foram induzidos à anestesia geral, ao receberem como pré-medicação midazolan $^{7}$ $(0,15 \mathrm{mg} / \mathrm{kg}, \mathrm{IV})$ e infusão sob pressão de éter gliceril guaiacol $^{8}$ a $10 \%(100 \mathrm{mg} / \mathrm{kg} \mathrm{IV})$, seguida de tiopental $^{9}(12,5 \mathrm{mg} / \mathrm{kg} \mathrm{IV})$. Após intubação orotraqueal, a manutenção anestésica foi feita com halotano ${ }^{10}$ volatilizado em $15 \mathrm{ml} / \mathrm{kg}$ de oxigênio, em circuito anestésico semi-fechado com ventilação controlada ${ }^{11}$. Durante o

\footnotetext{
${ }^{3}$ Neocaína 0,5\%-Cristália - Itapira, Brasil.

${ }^{4}$ Xilestesin sem vasoconstritor - Cristália - Itapira, Brasil.

${ }^{5}$ Fisiógrafo- Mod. 7-8p24.5, Grass - EUA.

${ }^{6}$ Vycril 2-0 - Eticon - EUA.

${ }^{7}$ Dormire - Cristália - Itapira, Brasil.

${ }^{8}$ Éter gliceril Guaiacol - Henryfarma Ltda. - São Paulo, Brasil.

${ }^{9}$ Tiopental - Cristália - Itapira, Brasil.

${ }^{10}$ Halotano - Cristália - Itapira, Brasil.

${ }^{11}$ Aparelho de Anestesia, Mod. 28003; Mallardiric - EUA.
}

procedimento cirúrgico, foram administrados $5 \mathrm{a}$ $10 \mathrm{ml} / \mathrm{kg} / \mathrm{min}$, IV, de solução de Ringer com lactato para auxiliar a manutenção da pressão arterial média, entre 70 e $100 \mathrm{mmHg}$. Quando a fluidoterapia não era suficiente para este fim, administrava-se dobutamina ${ }^{12}$, na dose de 1 a $5 \mu \mathrm{g} / \mathrm{kg} / \mathrm{min}$.

Foram realizadas celiotomias medianas retroumbilical, com incisão de aproximadamente $25 \mathrm{~cm}$, para permitir a exposição do cólon menor distendido. Completado o período de quatro horas de isquemia, retirou-se o manguito dos animais do G1 e desobstruiu-se o lúmen dos animais do G2 por meio do esvaziamento e da retirada do manguito. Após nova síntese da enterotomia e irrigação da área com Ringer lactato, realizou-se a laparorrafia, segundo técnica de rotina e, em seguida, permitiu-se a recuperação anestésica do animal.

No início do período de recuperação, os animais receberam $0,005 \mathrm{mg} / \mathrm{kg}$ IM de buprenorfina ${ }^{13} \mathrm{e}$ foram colocados em baias individuais até completar o período de 12 horas de reperfusão. Ao final desse período, foram sedados com xilazina ${ }^{1} 10 \%(1 \mathrm{mg} / \mathrm{kg}, \mathrm{IV})$; a anestesia geral foi induzida por tiopental ${ }^{12}(10 \mathrm{mg} / \mathrm{kg}$, IV) e a eutanásia foi realizada por meio de infusão intravenosa de solução saturada de sulfato de magnésio.

Foram colhidas amostras de sangue de todos os grupos para a realização do proteinograma, antes do início do procedimento (M1), após quatro horas da colocação do manguito (M2) e após três horas (M3) e 12 horas (M4) de reperfusão. O sangue para a realização do proteinograma foi colhido em frascos estéreis e sem anticoagulante.

As amostras, fracionadas em três alíquotas, para minimizar o risco de perda do material, foram acondicionadas em frascos criogênicos estéreis e imediatamente congelados à temperatura de $180^{\circ} \mathrm{C}$, até o momento da realização do proteinograma, de acordo com o protocolo adotado por Faleiros et al. (2002a).

Os valores das proteínas totais do soro foram obtidos por espectrofotometria para a separação das proteínas séricas, mediante fracionamento

\footnotetext{
${ }^{12}$ Dobutrex - ABL Antibióticos - São Paulo, Brasil.

${ }^{13}$ Tengesic - Schering-Plough - São Paulo, Brasil.
} 
eletroforético em gel de poliacrilamida contendo dodecil sulfato de sódio (SDS-PAGE). As frações das proteínas, determinadas por densitometria computadorizada ${ }^{14}$, foram identificadas utilizando-se como referência um marcador com pesos moleculares (PM) de 29.000 Da, 45.000 Da, 66.000 Da, 116.000 Da e 205.000 Da e por comparação da mobilidade da $\alpha_{1}$-antitripsina purificada. Os valores das concentrações das proteínas constituintes de cada fração foram determinados pela proporção dessas em relação aos valores da proteína total de cada momento.

\section{RESULTADOS E DISCUSSÃO}

Para os animais deste ensaio, as possíveis proteínas de fase aguda encontradas foram: ceruloplasmina, $130.000 \mathrm{Da}$; proteína C-reativa, 122.000 Da; transferrina, $85.000 \mathrm{Da} ; \alpha_{1}$ - antitripsina, $61.000 \mathrm{Da}$; haptoglobina, 47.000 Da; e glicoproteína ácida, 40.000 Da. Os valores obtidos no proteinograma sérico são apresentados na Tab. 1.

Neste estudo, utilizou-se a técnica de SDSPAGE com base nos relatos de Kaneko et al. (1997) que afirmaram que o fracionamento eletroforético representa um dos mais confiáveis métodos de identificação de proteínas dos fluidos corporais. Utilizando essa técnica, Fagliari et al. (1997) identificaram 19 frações no proteinograma sérico de eqüinos com laminite.

A estocagem do soro em nitrogênio líquido mostrou ser eficiente na preservação do material, pois, independente da data da coleta do material, todas as amostras tiveram o mesmo comportamento na corrida do gel de poliacrilamida (SDS-PAGE).

Tabela 1. Proteinograma de eqüinos submetidos à obstrução intraluminal (G1) e à obstrução intraluminal com isquemia intramural e reperfusão do cólon menor $(\mathrm{G} 2)$ e diferenças porcentuais nas concentrações protéicas entre os momentos M1 (antes da intervenção cirúrgica), M2 (com quatro horas da colocação do manguito), M3 (com três horas de reperfusão) e M4 (com 12 horas de reperfusão)

\begin{tabular}{|c|c|c|c|c|c|}
\hline Proteína & Grupo & M1 & M2 & M3 & M4 \\
\hline \multirow{3}{*}{ Ceruloplasmina } & G1 & 33,8 & 42,3 & 78,5 & 0 \\
\hline & $\mathrm{G} 2$ & 0 & 106,7 & 17 & 3,7 \\
\hline & $\%$ & 0 & 152,2 & $-78,3$ & 0 \\
\hline \multirow{3}{*}{ C-reativa } & G1 & 0 & 15,7 & 31,8 & 9,1 \\
\hline & $\mathrm{G} 2$ & 22,2 & 27,2 & 6,3 & 0 \\
\hline & & 0 & 73,2 & $-80,1$ & 0 \\
\hline \multirow{3}{*}{ Transferrina } & G1 & 176,5 & 60,4 & 175,3 & 197,2 \\
\hline & $\mathrm{G} 2$ & 97,3 & 74,6 & 62,9 & 111,1 \\
\hline & & $-44,8$ & 23,5 & $-64,1$ & $-43,6 \%$ \\
\hline \multirow{3}{*}{$\alpha_{1}$-antitripsina } & G1 & 63,1 & 48 & 43,7 & 31,8 \\
\hline & G2 & 125,8 & 33,3 & 38,3 & 122,2 \\
\hline & & 99,3 & $-30,6$ & $-12,3$ & 284,2 \\
\hline \multirow{3}{*}{ Haptoglobina } & G1 & 69,7 & 138 & 147,7 & 110,1 \\
\hline & $\mathrm{G} 2$ & 103,9 & 106,7 & 100,3 & 94,5 \\
\hline & & 49 & $-22,6$ & -32 & $-14,1$ \\
\hline \multirow{3}{*}{$\begin{array}{l}\text { Glicoproteína } \\
\text { ácida }\end{array}$} & G1 & 15,2 & 46,4 & 130,9 & 73,1 \\
\hline & $\mathrm{G} 2$ & 59,4 & 22,4 & 27,6 & 21,2 \\
\hline & & 290,7 & $-51,7$ & $-78,9$ & $-70,9$ \\
\hline
\end{tabular}

A concentração plasmática de proteínas na fase aguda, segundo Kent (1992), é diretamente proporcional ao grau de lesão tecidual ou de inflamação, assim, espera-se que os animais submetidos ao trauma cirúrgico apresentem maior nível protéico (Whicher e Dieppe, 1985;

${ }^{14}$ Shimadzu-CS-9301PC - Tóquio, Japão 
Gruys et al., 1994). Os resultados encontrados assemelham-se aos dos autores citados, visto que a análise dos traçados obtidos em gel de poliacrilamida dos animais do grupo distendido (G2) mostra elevação protéica, sendo as proteínas mais precocemente elevadas as que apresentaram pesos moleculares de $130.000 \mathrm{Da}$ ceruloplasmina, $122.000 \mathrm{Da}$ - proteína C-reativa e $85.000 \mathrm{Da}$ - transferrina, cujos percentuais de elevação, quatro horas após a intervenção cirúrgica (M2) foram 152\%, 73,2\% e 23,5\%, respectivamente. Os animais do G1, não submetidos à obstrução, mas somente à instrumentação cirúrgica, exibiram perfil eletroforético distinto, sendo que as maiores concentrações das proteínas: ceruloplasmina 130.000 Da, proteína c-reativa - $122.000 \mathrm{Da}$, haptoglobina - 47.000 Da, e glicoproteína ácida 40.000 Da ocorreram na terceira hora de reperfusão (M3); a maior concentração da transferrina - 85.000 Da, na $12^{\mathrm{a}}$ hora de reperfusão (M4) e a da $\alpha_{1}$-antitripsina - 61.000 $\mathrm{Da}$, antes do procedimento cirúrgico.

O resultado que mostra a elevação da ceruloplasmina assemelha-se ao obtido por Okumura et al. (1991), que utilizaram eqüinos com sinais clínicos de inflamação e registraram alteração na concentração dessa proteína. A identificação da proteína C-reativa confirma as citações de Conner et al. (1988) que, após induzirem trauma cirúrgico em cães, identificaram-na, registrando seu valor máximo em 24 horas. Segundo Kaneko et al. (1997), a transferrina é uma proteína de fase aguda negativa, ou seja, diminui sua concentração no soro. No G2, esse mesmo padrão foi encontrado. Observou-se também que, com 12 horas de reperfusão (M4), houve aumento na concentração sérica da transferrina em ambos os grupos, indicando que PFA negativa ou positiva relaciona-se apenas ao seu metabolismo hepático, e não ao seu comportamento no soro (Fagliari e Silva, 2002).

Em G2, a glicoproteína ácida e a haptoglobina tenderam ao decréscimo ao longo do tempo, situação semelhante à encontrada por Fagliari e Silva (2002), sugerindo que sua síntese requer a presença de mediadores inflamatórios. Neste ensaio, observaram-se altas concentrações de glicoproteína ácida e haptoglobina logo após o trauma cirúrgico. Em relação à glicoproteína ácida, este resultado é semelhante às mensurações de Taira et al. (1992), que a isolaram em ruminantes, felinos e eqüinos após infecções, inflamações e tumores malignos. A concentração dessa proteína no sangue, segundo esses autores, determina o prognóstico de doenças inflamatórias e auxilia no monitoramento de estados imunossupressivos em humanos.

Conner et al. (1988) confirmaram a detecção da haptoglobina em ruminantes com infecções natural e experimental, sendo de $43 \%$ e $84 \%$ o aumento observado após $24 \mathrm{~h}$ e $72 \mathrm{~h}$, respectivamente. Os mesmos autores descreveram que a haptoglobina é um bom indicador de afecções sistêmicas em felinos. Sabe-se, ainda, que os níveis de haptoglobina aumentam 24 horas após a cirurgia e dobram suas concentrações em quatro dias. Esse comportamento é diferente dos resultados que este ensaio apresentou até a $12^{\mathrm{a}}$ hora de reperfusão, pois os valores séricos tenderam ao declínio.

O comportamento da $\alpha_{1}$-antritripsina - 61.000 $\mathrm{Da}$, nos animais do G2, mostrou percentual de elevação diferenciado, com $284,2 \%$ na terceira hora de reperfusão (M3) em relação ao G1. Neste grupo, o teor da $\alpha_{1}$-antitripsina oscilou ao longo dos momentos experimentais, confirmando $\mathrm{o}$ comportamento de uma proteína de fase aguda, apresentado por Kaneko et al. (1997), e confirmando os resultados obtidos por Fagliari et al. (1997), que constataram alterações nos níveis séricos após a indução de laminite, em pôneis.

Os menores percentuais constatados no G2 foram nas concentrações de ceruloplasmina, proteína creativa, transferrina, haptoglobina e glicoproteína ácida na terceira hora de reperfusão (M3), com percentuais de diminuição de $-78,3 \%,-80,1 \%$, $64,1 \%,-32 \%$ e $-78,9 \%$, respectivamente. Os animais de G1 apresentaram comportamento diverso, com diminuição dos teores de ceruloplasmina e $\alpha_{1}$-antritripsina na $12^{\mathrm{a}}$ hora de reperfusão (M4), dos teores de proteína C-reativa e haptoglobina logo após a intervenção cirúrgica (M1), e dos teores de transferrina e glicoproteína ácida na quarta hora de colocação do manguito (M2). 


\section{CONCLUSÕES}

A eletroforese em acrilamida (SDS-PAGE) possibilitou detectar alterações em todos os animais submetidos à obstrução experimental do cólon menor. Tais alterações perduraram durante o período de reperfusão, no entanto o período estabelecido parece não ter sido suficiente para determinar por quanto tempo tais alterações se manteriam. $\mathrm{O}$ modelo utilizado mostrou que as proteínas de fase aguda são importantes para os eqüinos, em razão da alteração de seus valores após os procedimentos cirúrgicos.

\section{REFERÊNCIAS BIBLIOGRÁFICAS}

CONNER, J.G.; ECKERSALL, P.D.; FERGUSON, $\mathrm{J}$. et al. Acute phase response in the dog following surgical trauma, Vet. Sci., v.45, p.107-110, 1988.

EDINGER, H.; MILLER, I.; STANEK, C. et al. Electrophoretic studies of serum protein fractions in horses with laminitis. Dtsch. Tierarztl., v.99, p.426430, 1992.

FALEIROS, R.R.; ALVES, G.E.S.; SANTOS, R.L. et al. Experimental ischemia and reperfusion in equine small colon. Arq. Bras. Med. Vet. Zootec., v.53, p.341-350, 2002a.

FALEIROS, R.R.; MACORIS, D.G.; ALESSI, A.C. et al. Effect of intraluminal distention on microvascular perfusion in the equine small colon. Am. J. Vet. Res., v.63, p.1292-1297, 2002b.

FAGLIARI, J.J.; McCLENAHAN, D.; EVANSON, O.A. et al. Changes in plasma proteina concentrations in ponies with experimentally induced alimentary laminitis. Am. J. Vet. Res., v.59, p.1234-1237, 1997.

FAGLIARI, J.J.; RIZOLLI, F.W.; SILVA, S.L. et al. Proteinograma sérico de bezerros recémnascidos da raça Holandesa obtido por eletroforese em gel de poliacrilamida. Arq. Bras. Med. Vet. Zootec., v.58, p.450-453, 2006.

FAGLIARI, J.J.; SILVA, S.L. Hemograma e progeinograma de eqüinos hígidos e de eqüinos acometidos por abdômen agudo, antes e após laparotomia. Arq. Bras. Med. Vet. Zootec., v.54, p.559-567, 2002.
GORDON, A.H. Electrophoresis of proteins in polyacrylamide and starch gels. New York: Elsevier, 1995. 213p.

GRUYS, E.; OBWOLO, M.J.; TOUSSAINT, M.J.M. Diagnostic significance of the major acute phase proteins in veterinary clinical chemistry: a review. Vet. Bull., v.64, p.1009-1018, 1994.

KANEKO, J.J.; HARVEY, J.W.; BRISS, M.C. Clinical biochemistry of domestic animals. 6.ed. San Diego: Academic, 1997. 932p.

KENT, J. Acute phase proteins: their use in veterinary diagnosis. Br. Vet. J., v.148, p.279-282, 1992.

MATTEWS, A.G. Serum protein electrophoresis in horse and ponies. Equine Vet. J., v.14, p.322-324, 1982.

NUNOKAWA, Y.; FUJINAGA, T.; TAIRA, T. et al. Evaluation of serum amyloid A protein as an acute-phase reactive protein in horses. J. Am. Vet. Med. Assoc., v.55, p.1011-1016, 1993.

OKUMURA, M.; FUJINAGA, T.; YAMASHITA, $\mathrm{K}$. et al. Isolation, characterization, and quantitative analysis of ceruloplasmin from horses. Am. J. Vet. Res., v.52, p.1979-1985, 1991.

SILVA, L.C.C.; FERREIRA, M.A., FANTONI, D. T. Estudo retrospectivo das afecções do intestino grosso em eqüinos, submetidos a laparotomia, no período de janeiro de 1992 a abril de 1998. In: CONGRESSO BRASILEIRO DE CIRURGIA E ANESTESIOLOGIA VETERINÁRIA, 3., 1998, Belo Horizonte. Anais... Belo Horizonte: Colégio Brasileiro de Cirurgia e Anestesiologia Veterinária, 1998. p.128.

SPEIRS, C.V. Clinical examination of horse. Pennsylvania: Saunders, 1997. 358p.

TAIRA, T.; FUJINAGA, T.; TAMURA, K. et al. Isolation and characterization of alfa- 1 acid glycoprotein from horses, and its evaluation as an acute-phase reactive protein in horse. Am. J. Vet. Res., v.53, p.961-965, 1992.

TAKIGUCHI, M.; FUJINAGA, T. NAIKI, M. et al. Isolation, characterization, and quantitative analysis of c-reative protein from horses. Am. J. Vet. Res., v.51, p.1215-1220, 1990.

WICHER, J. T.; DIEPPE, P.A. Acute phase proteins. Clin. Immunol. Allergy, v.5, p.425-446, 1985. 